\title{
Synthesis and Binding of a Novel PSMA-specific Conjugate
}

\author{
ANDERS R. HOLMBERG, MARCELA MARQUEZ, LENA LENNARTSSON, \\ LENNART MEURLING and STEN NILSSON
}

Department of Oncology and Pathology, Karolinska Institute, Stockholm, Sweden

\begin{abstract}
Background/Aim: Prostate-specific membrane antigen (PSMA) is emerging as a target for treatment of castration-resistant prostate cancer (CRPC) while its upregulated in the majority of CRPC tumors. The most common approach is targeted radionuclide therapy. Materials and Methods: The PSMA binding pharmacophore Glu-UreaLysine (GUL) and lysine were conjugated to oxidized dextran with reductive amination and subsequently labelled with fluorosceinisothiocyanate (FITC). Three prostate cancer cell lines were used for binding studies, 22Rv1 (PSMA positive), DU145 (PSMA negative) and PC3 (PSMA negative). Binding images were obtained by fluorescence microscopy. Results: $P D C$ binding was recorded on the $22 R v 1$ cell line while the negative cell lines showed no or slight background binding. PDC binding could be inhibited by pre-incubation with a molar excess of unlabelled PDC. Conclusion: This is a novel template for PSMA targeted CRPC therapy, either using cytostatics or radionuclides.
\end{abstract}

The definition of castration-resistant prostate cancer (CRPC) is any progression, biochemical or clinical, that takes place in the presence of castrate level testosterone values (1). The possibilities to treat this stage of prostate cancer (Pca) have changed in a positive direction during the past 12 years. Before 2004, treatment options for CRPC patients were limited to palliative chemotherapy (mitoxantrone), best supportive care and palliative radiation therapy/corticosteroids, all without any overall survival benefit. In 2004 it was reported that docetaxel could improve the survival and it became the standard for several years $(2,3)$. Later that decade, carbazitaxel was introduced, a development from docetaxel (4). After 2010, three new drugs positively affecting overall survival have

Correspondence to: Dr. Anders R. Holmberg, Karolinska Institute, CCK, R8/00, 17176 Stockholm, Sweden. Tel: +46 8 51774408, email: arh@telia.com

Key Words: CRPC, PSMA, dextran, tripeptide, prostate cancer cell lines, fluorescence microscopy. been introduced, abiraterone (5), enzalutamide (6) and Radium-223 (7). These new drugs for treatment of CRPC have additional patient benefits improving quality of life, e.g. decreasing associated pain and delaying skeletal morbidity. In spite of these significant improvements the average survival time of the CRPC patient continues to be rather short. When calculating the median survival time for CRPC patients participating in a large number of phase 3 trials, the survival figure is only 19 months (8). Consequently, the need for new effective CRPC therapies continues to be big and current research is looking for new CRPC exclusive targets. One promising target is prostate specific membrane antigen (PSMA) and radiolabelled PSMA binding ligands are considered as a milestone in CRPC management (9). PSMA is a type II integral membrane glycoprotein and is a homologue of folate hydrolase I (10). It is frequently expressed in tumor neovasculature and is considered a reliable marker for Pca. Increasing PSMA expression correlates with Pca grade and almost all CRPC cases have up-regulated PSMA expression (11), seemingly making it an ideal target for targeted therapy. Among the first PSMA targeting agents was ${ }^{111}$ In-capromab, an Indium-111 labelled anti-PSMA antibody for diagnostic purposes. However, because of inherent limitations resulting in low tumor to background ratios, its application has remained limited (12). New antiPSMA antibodies have been developed with promising properties $(13,14)$, however still with their major limitation of long circulating half-life and poor tumor penetration, all due to the molecular weight of antibodies. To overcome some of these limitations, small-molecule PSMA binding inhibitor ligands are being investigated, mostly for imaging purposes labelled with suitable radionuclides (15). The compounds can be classified into three groups, urea-glutamate based, phosphoramidates and 2-(phosphinylmethyl)pentanedioic acids.

The present study describes the synthesis and PSMA binding of a Glu-Urea-Lys-Dextran conjugate (PDC). This construct is polydisperse, owing to its dextran backbone, with an average molecular weight of that of an $\mathrm{IgG}$ fragment (Fv) i.e. approximately $25 \mathrm{kD}$. 


\section{Materials and Methods}

PDC for fluorescence microscopy, synthesis. Dextran 40 PhEUR (Pharmacosmos AS, Holboek, Denmark) was used as conjugate backbone. Sodium metaperiodate (Merck AG, Darmstadt, Germany) was used for oxidation/activation. L-Lysine (Sigma Aldrich, Stockholm, Sweden) and the PSMA ligand Glutamate-Urea-Lysine (GUL) were used for the conjugation (Peptides \& Elephants, Potsdam, Germany). Sodium cyanoborohydride (Sigma Aldrich, Stockholm, Sweden) was used for reductive amination. PD-10 disposable Sephadex G-25 columns were used for separation and purification (G\&E Biotech AB, Uppsala, Sweden). FITC was from Sigma Aldrich, Stockholm, Sweden.

Activation and conjugation. $30 \mathrm{mg}$ of dextran was mixed with $18 \mathrm{mg}$ of sodium periodate in $1 \mathrm{ml}$ of distilled $\mathrm{H} 2 \mathrm{O}$ and the $\mathrm{pH}$ was adjusted to 1,6 with $\mathrm{H}_{2} \mathrm{SO}_{4}$. The mixture was incubated on a magnetic stirrer for $45 \mathrm{~min}$, at room temperature and in the dark.

Conjugation: $30 \mathrm{mg}$ of activated dextran was mixed with $20 \mathrm{mg}$ GUL in $1 \mathrm{ml} 0.2 \mathrm{M}$ Sodium phosphate buffer at $\mathrm{pH} \mathrm{7,4+5} \mathrm{mg}$ sodium cyanoborohydride and then incubated in the dark at room temperature for $120 \mathrm{~min}$ on a magnetic stirrer. After $120 \mathrm{~min}, 12$ $\mathrm{mg}$ lysine was added and the incubation continued for an additional $60 \mathrm{~min}$. After $4 \mathrm{~h}$ of total incubation, the solution was purified on a PD-10 column using $20 \mathrm{mM}$ borate buffer at $\mathrm{pH} 9,5$ as eluent.

FITC labelling: $15 \mathrm{mg}$ of conjugate in $1 \mathrm{ml}$ borate buffer at $\mathrm{pH}$ 9,5 was mixed with $50 \mu \mathrm{g}$ FITC and incubated in the dark at room temperature for $18 \mathrm{~h}$. After incubation, the conjugate was purified on a PD10 column and eluted in sodium acetate at pH 6.

Cell line and culture conditions. The human metastatic prostate carcinoma cell lines 22Rv1, DU145 and PC3 obtained from the American Type Culture Collection (ATCC, Teddington, U.K. . The cell lines were cultured in $5 \mathrm{ml}$ dishes (Falcon, Fisher Scientific, Göteborg, Sweden) with RPMI 1640 (Sigma Aldrich, Stockholm, Sweden). $2 \mathrm{mM}$ glutamine (Sigma Aldrich, Stockholm, Sweden), $10 \%$ fetal calf serum (Life Technologies, Carlsbad, USA) and 1\% penicillin/streptomycin (Gibco, Fischer Scientific, Göteborg, Sweden) were added to the media. The cells were kept in a $37^{\circ} \mathrm{C}$ incubator with humidified air and $5 \% \mathrm{CO}_{2}$. The culture medium was changed twice a week. Cells were removed from the dishes by treatment with trypsin $(0,5 \mathrm{~g})$-EDTA $(0,2 \mathrm{~g})$ (Sigma Aldrich, Stockholm, Sweden). The cells were seeded on 8 chamber glasses 50,000 in each well, 2 wells for each cell line. Following incubation for $24 \mathrm{~h}$, the cells were rinsed in phosphate buffered saline (PBS) and incubated with PDC-FITC conjugate with or without blocking/inhibition with molar excess of unlabelled PDC (all in PBS at room temperature). PDC at a concentration of $25 \mu \mathrm{M}$ was used to inhibit the PDC-FITC conjugate PSMA binding. After $10 \mathrm{~min}$ the PDC-FITC conjugate was added at a concentration of $2.5 \mu \mathrm{M}$. The cells without blocking were only treated with PDC-FITC at $2.5 \mu \mathrm{M}$ for $10 \mathrm{~min}$. After another $10 \mathrm{~min}$ the cells were rinsed carefully in PBS and fixed in $4 \%$ formaldehyde for $10 \mathrm{~min}$. The slides were then mounted with mounting media with DAPI (4',6-Diamidino-2Phenylindole Dihydrochloride, Vectashield, Vector labs, Burlingame, California USA). The slides were visualised in a Zeiss microscope and photos were obtained using Axiovision software.
PDC, GUL substitution: In order to facilitate optimisation and analysis of the conjugation of GUL, in a separate synthesis, as described above, para-amino-benzoic acid (PABA, Sigma Aldrich, Darmstadt, Germany) was included in the GUL synthesis i.e. PABA was substituted to the lysine residue of GUL (Peptides \& Elephants, Potsdam, Germany) and conjugation to dextran was done through the aromatic amine of PABA. Hence a PABA standard curve was prepared at A280 using a spectrophotometer (Genesis 10S, ThermoFisher Scientific, Göteborg, Sweden) and was used for determination of GUL conjugate substitution.

$P D C$, conjugation of radio nuclide metal chelator: To demonstrate the versatility of the PDC conjugate, Gd.(2-4aminobenzyl)-1,4,7,10tetraaazacyclodocecane-1,4,7,10-tetraacetate (DOTA, from Macrocyclics inc, Texas, USA) was included in the conjugation synthesis described above i.e. after the GUL coupling, $40 \mathrm{mg}$ DOTA was added, together with $12 \mathrm{mg}$ lysine. Hence, a DOTA standard curve was prepared at A280 using a spectrophotometer (Genesis 10S, ThermoFisher Scientific, Göteborg, Sweden) and was used for determination of DOTA-Gd conjugate substitution.

\section{Results}

The principal molecular structure of PDC and the different ligands are illustrated in Figure 1.

On average, 15-20 GUL ligands were conjugated yielding high PSMA avidity. When DOTA was conjugated, on average, 5-20 DOTA could be coupled, depending on the conditions chosen. In general, when coupling radio metal chelators, like the model compound used (DOTA), it is possible to modulate the number of chelators conjugated by modifying coupling time and molar proportions. When radio labelling PDC with therapeutic nuclides is desired, only a few conjugated chelates is required.

For the fluorescence microscopy studies to estimate PDC binding to PSMA positive tumor cells, PDC was FITC labelled. PDC-NH2 reacted with FITC-N=C=S yielding PDC-FITC through a resulting thiourea bond.

Binding of PDC-FITC $(2.5 \mu \mathrm{M})$ to PSMA positive cellline 22Rv1 is shown in Figure 2.

Background binding of the PDC-FITC conjugate $(2.5 \mu \mathrm{M})$ to PSMA negative cell-lines DU-145 and PC 3 is shown in Figures 3 and 4.

Binding of PDC-FITC $(2.5 \mu \mathrm{M})$ to PSMA positive cellline 22Rv1 inhibited by pre-incubation with molar excess of PDC without label $(25 \mu \mathrm{M})$ is shown in Figure 5.

Substitution with DOTA did not seem to affect the PDC binding to the PSMA positive cell line and nor did conjugated PABA substituted GUL have any apparent negative effect on the PDC binding. Excess free GUL ligand could inhibit the PDC-FITC binding but seemed to be displaced by PDC-FITC probably due to the superior avidity of the conjugate. Preincubation with unlabelled PDC effectively inhibited the PDCFITC binding. PDC without conjugated GUL could not inhibit the PDC-FITC binding to the 22Rv1 cell line. Hence, the PDC binding is apparently PSMA specific. 


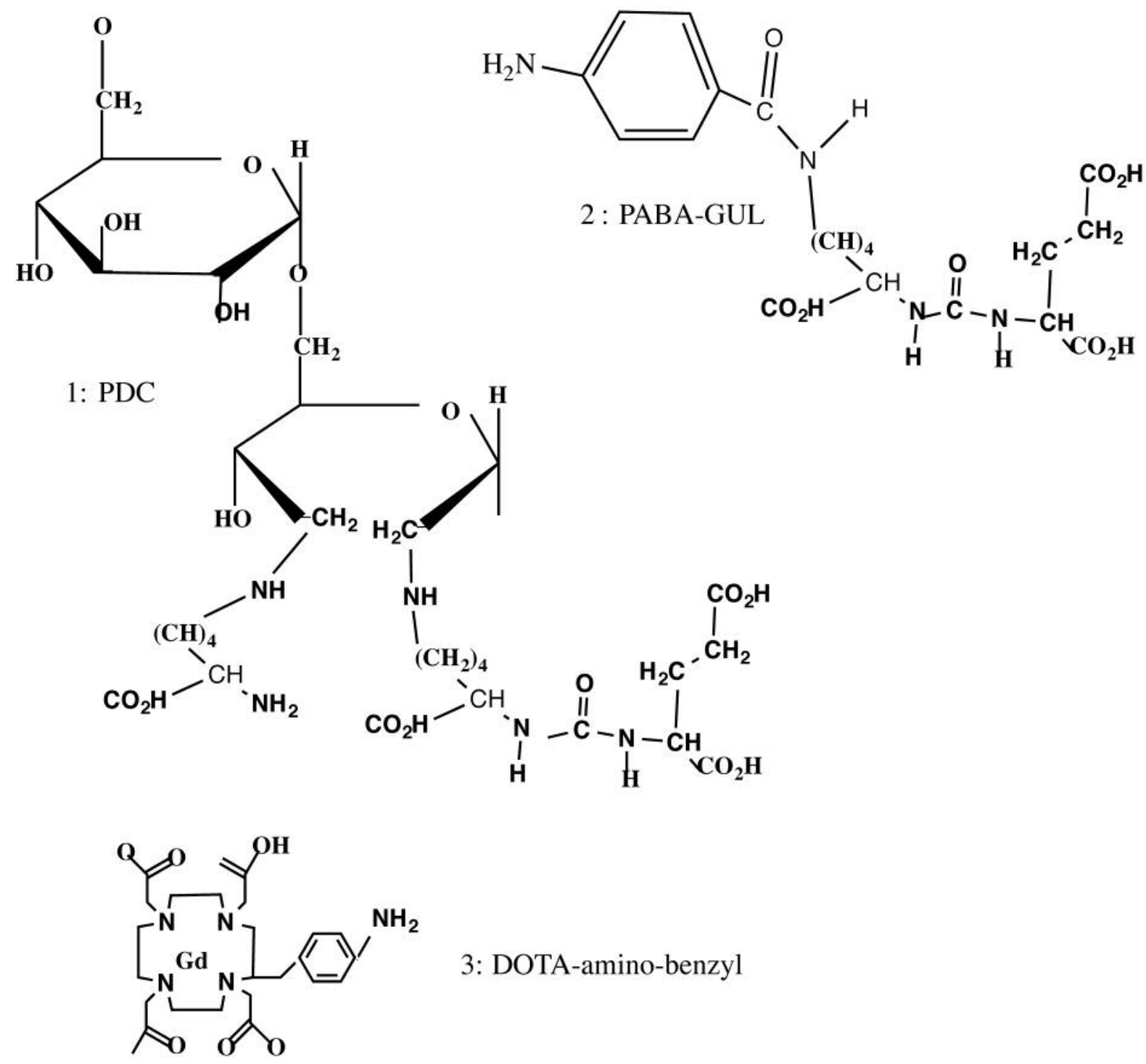

Figure 1. Showing PDC, the dextran-lysine-GUL conjugate, the GUL pharmacophore labelled with PABA and the DOTA benzyl-amine.

\section{Discussion}

The management of CRPC cancer remains a challenge in spite of significant progress during the last decade. CRPC continues to be incurable and eventually all patients succumb to their disease with an average overall survival of approximately 19 months (16). The progress in terms of prolongation of survival is limited to a handful of drugs currently approved for CRPC treatment, i.e. docetaxel, cabazitaxel, abiraterone, enzalutamide and radium-223. The average survival advantage is between 1.9 to 5.2 months. The most favourable order to use these drugs remains to be established.
PSMA is expressed in the vast majority of CRPC lesions, in soft tissue as well as in bone metastasis, and appears to be a highly suitable target for diagnostic and therapeutic intervention $(17,18)$. Due to inherent unfavourable properties of monoclonal antibodies, e.g. long systemic halflife and poor tumor penetration, PSMA radionuclide targeting currently appears to be mostly focused on using small molecule PSMA binding ligands. The small molecule pharmacophore is radiolabelled by introducing a radio metal chelator often via a spacer (19). Human studies are explorative and the majority are for diagnostic purposes using PET imaging with ligands labelled with ${ }^{68} \mathrm{Ga}$ and ${ }^{18} \mathrm{~F}$, demonstrating superior efficacy compared to standard 


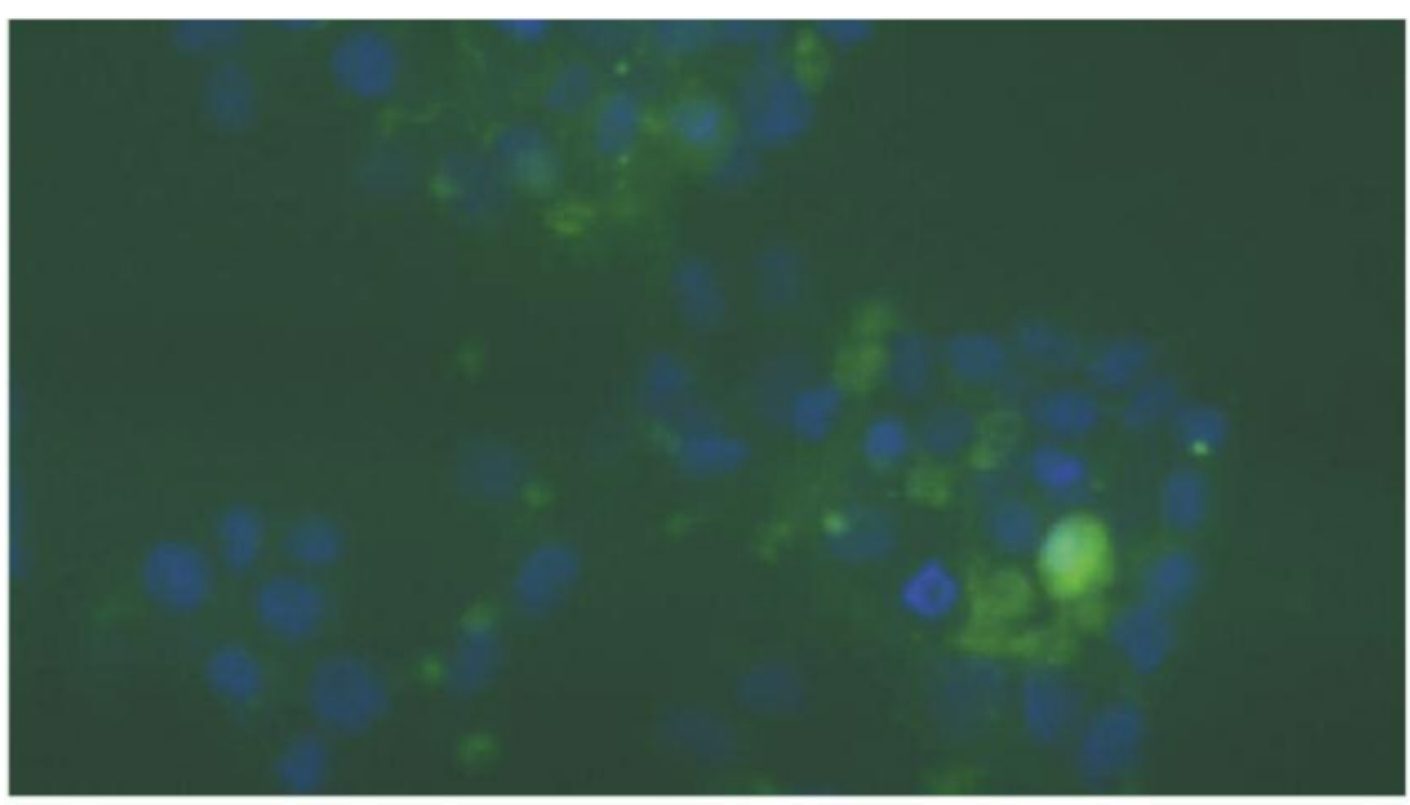

Figure 2. Fluorescence microscopy, FITC labelled PDC at $2.5 \mu \mathrm{M}$ binding to PSMA positive cell-line 22Rv1.

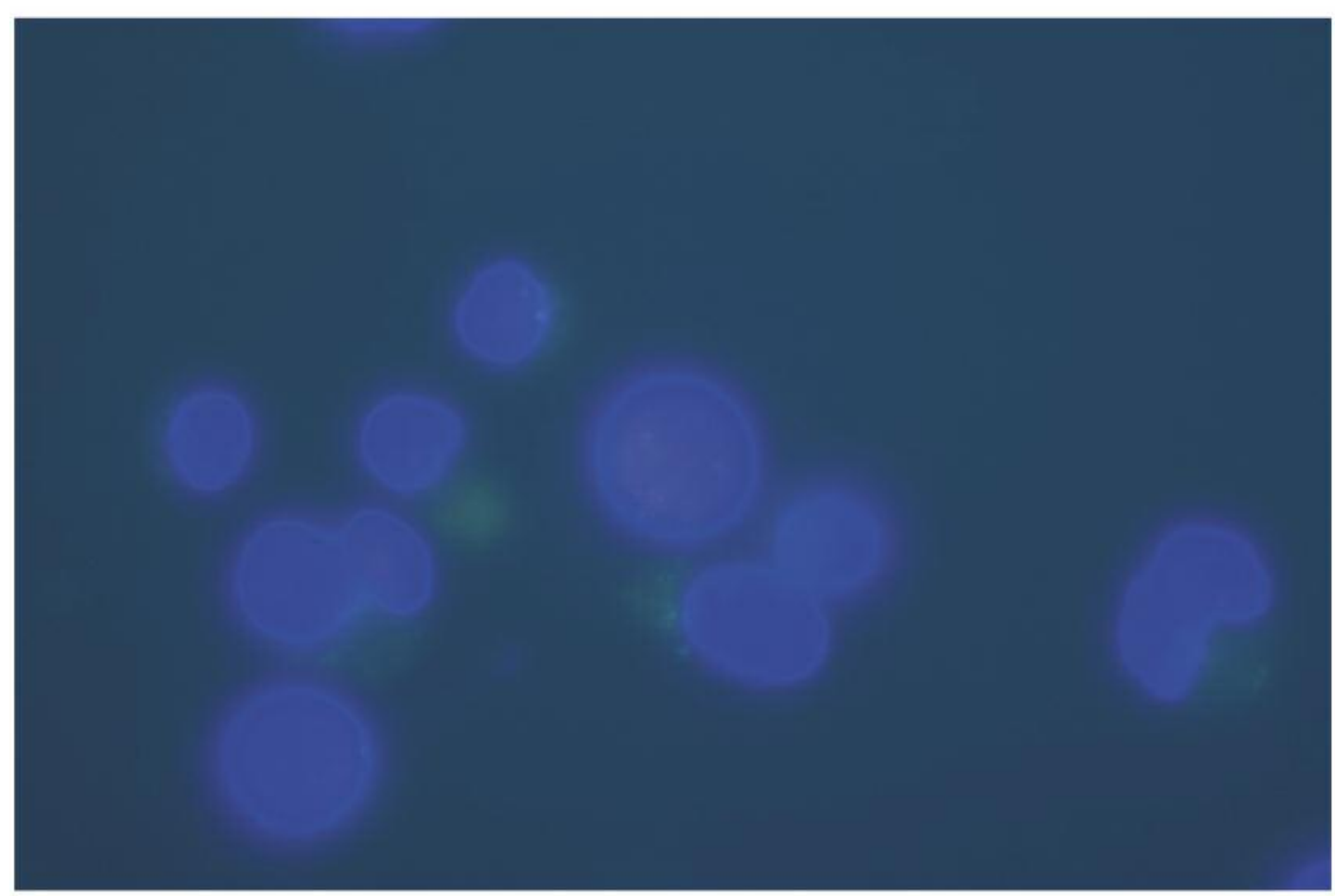

Figure 3. Fluorescence microscopy, background binding of FITC labelled PDC at $2.5 \mu$ M to PSMA negative cell-line PC3.

imaging modalities (20). Improved diagnostic procedures impact treatment planning and spare the patient other diagnostic investigations, and help selecting those patients that would benefit from PSMA targeted therapy.
For radionuclide therapy targeting PSMA, ${ }^{177} \mathrm{Lu},{ }^{90} \mathrm{Y}$ and ${ }^{131}$ I labelled small pharmacophores have been investigated. Lutetium $\left({ }^{177} \mathrm{Lu}\right)$ appears to be the most promising therapeutic radionuclide, e.g. regarding logistics and 
Figure 4. Fluorescence microscopy, background binding of FITC labelled PDC at $2.5 \mu$ M to PSMA negative cell-line DU-145.

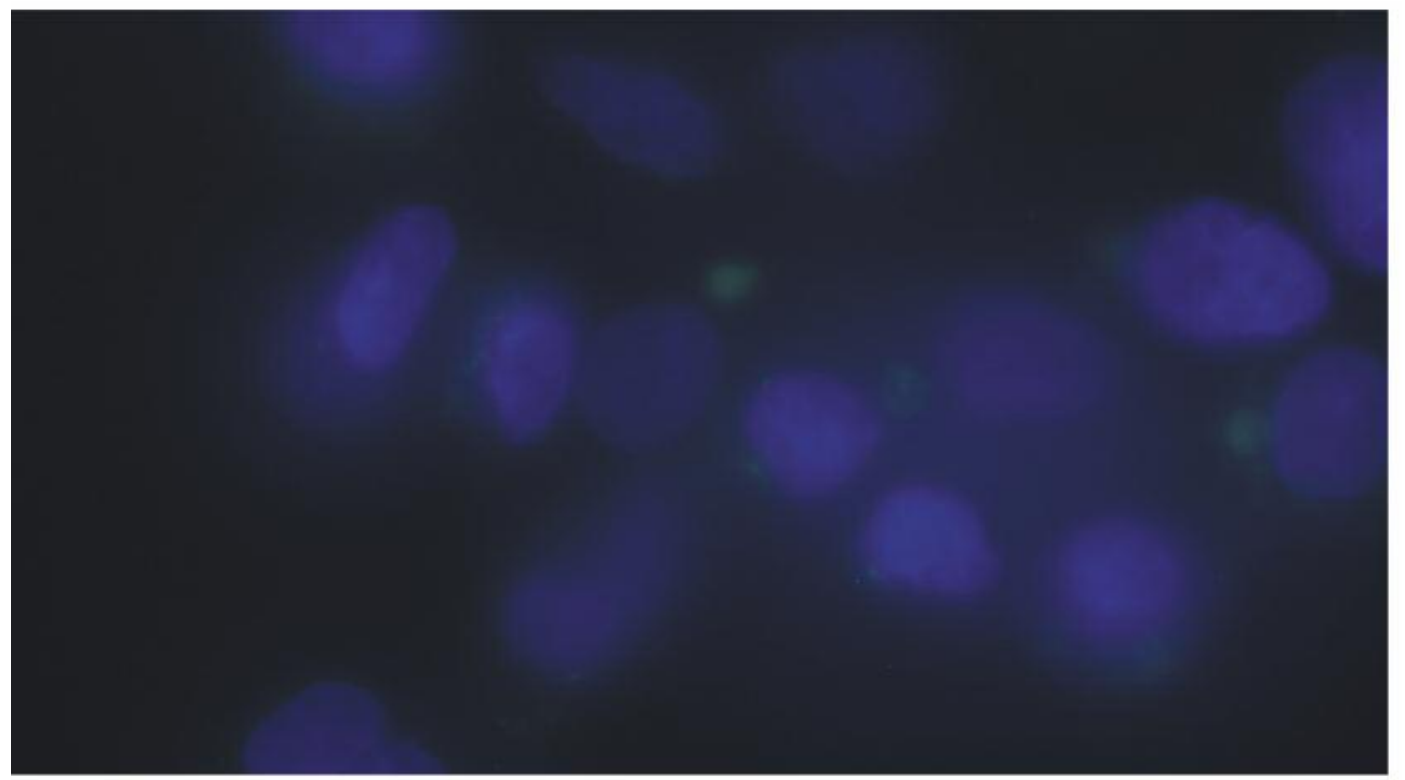

Figure 5. Fluorescence microscopy, Inhibition of FITC labelled PDC binding to 22Rv1 by unlabelled PDC at $25 \mu M$.

especially haematological toxicity, considering the close proximity between bone lesions and bone marrow. In general, ${ }^{177} \mathrm{Lu}$ labelled small pharmacophores have shown promising results with acceptable side effects (21).

Concerning PSMA targeted delivery of non-radioactive cytotoxic agents, antibody drug conjugates (ADC) have been studied using macrolide and dolastatin derivatives as cytotoxic agents (22). The effect of the ADC therapy seems modest and with side effects resembling systemic chemotherapy. There were also issues regarding the stability of the ADC constructs (linker deconjugation).

In perspective of this brief overview on agents for PSMA targeting in CRPC the construct reported in this paper is novel and different. PDC is a macromolecule with an 
approximate average m.w. of $25 \mathrm{kD}$, comparable to an antibody Fv fragment. Experience from similar constructs indicates a fast circulation clearance, high stability and beneficial safety profile $(23,24)$. The substitution of the PSMA binding pharmacophore can be modulated together with additional ligands, either a radio metal chelator, as in this study, DOTA suitable for ${ }^{177} \mathrm{Lu}$ and ${ }^{68} \mathrm{Ga}$, or a nonradioactive cytotoxic agent. The resulting PDC conjugate has superior avidity to the PSMA target, due to the combined strength of the multiple PSMA binding ligands coupled to the carbohydrate backbone. PDC can be considered as a template for PSMA targeting, either using radionuclides as therapeutic or with non-radioactive cytotoxic agents as a therapeutic moiety. When possible, as in this study, inclusion of an aromatic group to the ligands of interest very much facilitates the optimisation of the synthesis. Like this the synthesis yield in terms of substitution degree can easily be determined by spectrophotometric analysis. Concerning PSMA targeting with non-radioactive agents, for example, in addition to the PSMA binding moiety, PDC can be substituted with multiple guanidine side groups making PDC tumor cell cytotoxic (25).

On the subject of side-effects (adverse events, AE), the CRPC patient is often heavily pre-treated and especially vulnerable to $\mathrm{AE}$ that may have a negative effect on the patient's quality of life. Although most radiotherapy studies targeting PSMA report AE as "acceptable", two major risk organs have been recognized, the salivary glands and the lacrimal glands which express PSMA and are highly radiosensitive $(26,27)$. The radiotherapy may damage/ destroy these structures with resulting xerostomia (XS) and keratoconjuctivitis sicca (KCS). Both conditions may lead to serious secondary health issues and can have a very negative impact on quality of life. Examples of frequent problems connected with xerostomia contain sore throat, a burning oral discomfort, difficulty speaking, dysphagia, and dry nasal mucosa. Individuals with xerostomia also often develop gum disease and tooth loss. KCS symptoms include constant eye irritation, burning, itching, sense of pressure, grittiness and /or foreign body sensation. Consequently, the apparent risk of these side effects needs to be carefully considered in PSMA targeted therapy, weighing risk and patient benefit. Research efforts aiming at protection of these organs during therapeutic PSMA targeting is desirable.

In summary, this study describes a novel template for PSMA targeted therapy of CRPC, suitable for either radionuclides or cytotoxic agents as therapeutic moiety. PDC might have advantages compared to other constructs, especially in terms of producibility. Several of the explored PSMA targeting agents seem technically complicated to produce at a reasonable cost and therefore are not likely to become approved products to the benefit of the CRPC patients.
Further studies on the in vivo properties of PDC are in progress and will be reported later.

\section{Acknowledgements}

Supported by The Cancer Society in Stockholm, The King Gustav V Jubilee Fund, Stockholm, and The Swedish Cancer Society.

\section{References}

1 Scher HI, Halabi S, Tannock I, Morris M, Sternberg CN, Carducci MA, Eisenberger MA, Higano C, Bubley GJ, Dreicer R, Petrylak D, Kantoff P, Basch E, Kelly WK, Figg WD, Small EJ, Beer TM, Wilding G, Martin A and Hussain M; Prostate Cancer Clinical Trials Working Group: Design and end points of clinical trials for patients with progressive prostate cancer and castrate levels of testosterone: recommendations of the Prostate Cancer Clinical Trials Working Group. J Clin Oncol 26(7): 11481159, 2008

2 Petrylak DP, Tangen CM, Hussain MH, Lara PN Jr, Jones JA, Taplin ME, Burch PA, Berry D, Moinpour C, Kohli M, Benson MC, Small EJ, Raghavan D and Crawford ED: Docetaxel and estramustine compared with mitoxantrone and prednisone for advanced refractory prostate cancer. N Engl J Med 351: 15131520, 2004.

3 Tannock IF, de Wit R, Berry WR, Horti J, Pluzanska A, Chi KN, Oudard S, Théodore C, James ND, Turesson I, Rosenthal MA and Eisenberger MA; TAX 327 Investigators: Docetaxel plus Prednisone or mitoxantrone plus prednisone for advanced prostate cancer. N Engl J Med 351: 1502-1512, 2004.

4 de Bono JS, Oudard S, Ozguroglu M, Hansen S, Machiels JP, Kocak I, Gravis G, Bodrogi I, Mackenzie MJ, Shen L, Roessner M, Gupta S and Sartor AO; TROPIC Investigators: Prednisone plus cabazitaxel or mitoxantrone for metastatic castrationresistant prostate cancer progressing after docetaxel treatment: a randomised open-label trial. Lancet 376(9747): 1147-1154, 2010.

5 de Bono JS, Logothetis CJ, Molina A, Fizazi K, North S, Luis Chu L, Chi KN, Jones RJ, Goodman OB Jr., Saad F, Staffurth JN, Mainwaring P, Harland S, Flaig TW, Hutson TE, Cheng T, Patterson H, Hainsworth JD, Ryan CJ, Sternberg CN, Ellard SL, Fléchon A, Saleh M, Scholz M, Efstathiou E, Zivi A, Bianchini D, Loriot Y, Chieffo N, Kheoh T, Haqq CM and Scher HI; COUAA-301 Investigators: Abiraterone and increased survival in metastatic prostate cancer. N Engl J Med 364: 1995-2005, 2011.

6 Scher HI, Fizazi K, Saad F, Taplin ME, Sternberg CN, Miller K, de Wit R, Mulders P, Chi KN, Shore ND, Armstrong AJ, Flaig TW, Fléchon A, Mainwaring P, Fleming M, Hainsworth JD, Hirmand M, Selby B, Seely L and de Bono JS; AFFIRM Investigators: Increased survival with enzalutamide in prostate cancer after chemotherapy. N Engl J Med 367: 1187-1197, 2012.

7 Parker C, Nilsson S, Heinrich D, Helle SI, O'Sullivan JM, Fosså SD, Chodacki A, Wiechno P, Logue J, Seke M, Widmark A, Johannessen DC, Hoskin P, Bottomley D, James ND, Solberg A, Syndikus I, Kliment J, Wedel S, Boehmer S, Dall'Oglio M, Franzén L, Coleman R, Vogelzang NJ, O’Bryan-Tear CG, Staudacher K, Garcia-Vargas J, Shan M, Bruland ØS and Sartor O; ALSYMPCA Investigators: Alpha emitter radium-223 and survival in metastatic prostate cancer. N Engl J Med 369: 213223, 2013. 
8 West TA, Kiely BE and Stockler MR: Estimating scenarios for survival time in men starting systemic therapies for castrationresistant prostate cancer: a systematic review of randomised trials. Eur J Cancer 50(11): 1916-1924, 2014.

9 Pfestroff A, Luster M, Jilg CA, Olbert PJ, Ohlmann CH, Lassmann M, Maecke HR, Ezziddin S and Bodei L; Radionuclide Therapy Committee of the European Association of Nuclear Medicine: Current status and future perspectives of PSMA-targeted therapy in Europe: opportunity knocks. Eur J Nucl Med Mol Imaging 42(13): 1971-1975, 2015.

10 Lütje S, Heskamp S, Cornelissen AS, Poeppel TD, van den Broek SA, Rosenbaum-Krumme S, Bockisch A, Gotthardt M, Rijpkema $\mathrm{M}$ and Boerman OC: PSMA ligands for radionuclide imaging and therapy of prostate cancer: Clinical status. Theranostics 5(12): 1388-1401, 2015.

11 Wright GL Jr, Grob BM, Haley C, Grossman K, Newhall K and Petrylak D: Membrane antigen after androgen-deprivation therapy. Urology 48(2): 326-334, 1996.

12 Horoszewicz JS, Kawinski E and Murphy GP: Monoclonal antibodies to a new antigenic marker in epithelial prostatic cells and serum of prostatic cancer patients. Anticancer Res 7(5B): 927-935, 1987.

13 Bander NH, Trabusi EJ, Kostakoglu L, Yao D, Vallabhajosula S, Smith-Jones P, Joyce MA, Milowsky M, Nanus DM and Goldsmith SJ: Targeting metastatic prostate cancer with radiolabeled monoclonal antibody J591 to the extracellular domain of prostate specific membrane antigen. J Urol 170(5): 1717-1721, 2003.

14 Tagawa ST, Milowsky MI, Morris M, Vallabhajosula S, Christos P, Akhtar NH, Osborne J, Goldsmith SJ, Larson S, Taskar NP, Scher HI, Bander NH and Nanus DM: Phase II study of Lutetium-177-labeled anti-prostate-specific membrane antigen monoclonal antibody J591 for metastatic castration-resistant prostate cancer. Clin Cancer Res 19(18): 5182-5191, 2013.

15 Maresca KP, S. Hillier SM, Femia FJ, D. Keith D, C. Barone C, Joyal JL, Zimmerman CN, Kozikowski AP, Barrett JA, Eckelman WC and Babich JW: A series of halogenated heterodimeric inhibitors of prostate specific membrane antigen (PSMA) as radiolabeled probes for targeting prostate cancer. $\mathrm{J}$ Med Chem 52: 347-357, 2009.

16 West TA, Kiely BE and Stockler MR: Estimating scenarios for survival time in men starting systemic therapies for castration resistant prostate cancer: a systemic review of randomized trials. Eur J Cancer 50: 1916-1924, 2014.

17 Minner S, Wittmer C, Graefen M, Salomon G, Steuber T, Haese A. Huland H, Bokemeyer C, Yekebas E, Dierlamm J, Balabanov S, Kilic E, Wilczak W, Simon R, Sauter G and Schlomm T: High level PSMA expression is associated with early PSA recurrence in surgically treated prostate cancer. Prostate 71(3): 281-288, 2011.
18 Rybalov M, Ananias HJ, Hoving HD, van der Poel HG, Rosati $\mathrm{S}$ and de Jong IJ: PSMA, EpCAM, VEGF and GRPR as imaging targets in locally recurrent prostate cancer after radiotherapy. Int J Mol Sci 15(4): 6046-6061, 2014.

19 Huang SS, Wang X, Zhang Y, Doke A, DiFilippo FP and Heston WD: Improving the biodistribution of PSMA-targeting tracers with a highly negatively charged linker. Prostate 74(7): 702-713, 2014.

20 Schwarzenboeck SM, Rauscher I, Bluemel C, Fendler WP, Rowe SP, Pomper MG, Asfhar-Oromieh A, Herrmann K and Eiber M: PSMA ligands for PET imaging of prostate cancer. J Nucl Med 58(10): 1545-1552, 2017.

21 Kratochwil C, Giesel FL, Eder M, Afshar-Oromieh A, Benesova M Mier W, Kopka K and Haberkorn U: $\left[{ }^{177}\right.$ Lu]Lutetium-labelled PSMA ligand-induced remission in a patient with metastatic prostate cancer. Eur J Nucl Med Mol Imaging 42(6): 987-988, 2015.

22 Teo MY and Morris MJ: Prostate-membrane specific antigendirected therapy for metastatic castration-resistant prostate cancer. Cancer J 22(5): 347-352, 2016.

23 Thellenberg-Karlsson C, Nyman C, Nilsson S, Blom R, Márquez $\mathrm{M}$, Castellanos $\mathrm{E}$ and Holmberg AR: Bone-targeted novel cytotoxic polybisphosphonate conjugate in castration-resistant prostate cancer: A multicenter phase 1 study. Anticancer Res 36(12): 6499-6504, 2016.

24 Salehpour M, Håkansson K, Höglund U, Grahn-Westin A, Nilsson S, Márquez $M$, Possnert $G$ and Holmberg AR: Application of accelerator mass spectrometry to macromolecules: preclinical pharmacokinetic studies on a polybisphosphonate. Rapid Commun Mass Spectrom 25(17): 2371-2578, 2011.

25 Meurling L, Márquez M, Nilsson S and Holmberg AR: Polymerconjugated guanidine is a potentially useful anti-tumor agent. Int J Oncol 35(2): 281-285, 2009.

26 Hohberg M, Eschner W, Schmidt M, Dietlein M, Kobe C, Fischer T, Drzezga A and Wild M: Lacrimal glands may represent organs at risk for radionuclide therapy of prostate cancer with [(177)Lu]DKFZ-PSMA-617. Mol Imaging Biol 18(3): 437-445, 2016.

27 Grundmann O, Mitchell GC and Limesand KH: Sensitivity of salivary glands to radiation: from animal models to therapies. $\mathrm{J}$ Dent Res 88(10): 894-903, 2009.
Received November 29, 2017

Revised December 19, 2017

Accepted December 20, 2017 